\title{
A case of CLIPPERS syndrome responsive to tocilizumab
}

Torge Rempe, MD, Jos Steffen Becktepe, MD, Imke Metz, MD, Wolfgang Brück, MD, Klarissa Hanja Stürner, MD, Günther Deuschl, MD, Daniela Berg, MD, Ralf Baron, MD, Rainald Zeuner, MD, and Frank Leypoldt, MD

Neurol Neuroimmunol Neuroinflamm 2019;6:e545. doi:10.1212/NXI.0000000000000545

Chronic lymphocytic inflammation with pontine perivascular enhancement responsive to steroids (CLIPPERS) is an inflammatory disorder consisting of (1) subacute clinical brainstem signs and symptoms, (2) characteristic punctate and curvilinear perivascular peppercorn-like gadolinium enhancement of the pons, brachium pontis, and cerebellum in MRI, (3) dense perivascular $\mathrm{CD}^{+} \mathrm{T}$ cell predominant inflammatory cell infiltrates in biopsy, and (4) clinical and radiologic response to steroids in the absence of alternative diagnosis. ${ }^{1-3}$ There only exists sparse data from case reports regarding the use of corticosteroid-sparing agents with a probable therapeutic efficiency for methotrexate, cyclophosphamide, hydroxychloroquine, and azathioprine. ${ }^{4}$ Use and potential efficiency of the humanized monoclonal interleukin-6 receptor antagonist tocilizumab has not yet been reported in CLIPPERS.

\section{Case report}

In early 2007, after an upper respiratory tract infection, a 34-year-old female with no pertinent medical history started to gradually develop brainstem dysfunction (double vision, vertigo, and gait ataxia) and right occipital headache over a 3-month period. She also complained of brachiofacial paresthesias and prominent facial allodynia/hyperalgesia progressing to her upper chest.

Clinical neurologic examination showed diplopia when looking to the left, left-sided facial hypesthesia, positive right Babinski and bilateral Troemner reflexes as well as appendicular and truncal ataxia with a paraspastic and ataxic gait disorder.

MR imaging showed small infratentorial lesions in the pons, bilateral middle cerebral peduncles and medulla oblongata with associated strong "salt and pepper" like Gadolinium uptake, and linear appearance suggestive of a perivascular localization as well as an upper cervical spinal cord lesion (figure, A-E). Prominent extrapontine manifestations developed during the course of the disease (figure, $\mathrm{F}-\mathrm{H}$ ). Brain biopsy (right temporal lesion, figure, I-N) showed extensive perivascular, less marked vascular but also parenchymal infiltration of predominantly $\mathrm{CD} 4^{+}$ T-lymphocytes and few B-lymphocytes without features of vasculitis (no destruction of the vessel wall with fibrinoid necrosis, leukocytoclasia, or fibrin thrombi). These bioptic features have been noted as a hallmark in CLIPPERS. ${ }^{5}$ Few small necrotic lesions were evident. An extensive workup for known infectious, inflammatory, and neoplastic etiologies was negative.

From 2007 to 2011, the patient received multiple doses of IV methylprednisolone and intrathecal triamcinolone with clinical and radiologic improvement (figure, $\mathrm{O}$ ). However, this always only led to a short-term improvement with subsequent evidence of disease activity even under continued oral steroid tapers.

\author{
Correspondence \\ Dr. Leypoldt \\ frank.leypoldt@uksh.de
}


Figure Imaging, histology/immunohistochemistry, and schematic course of treatment with corresponding clinical and radiologic disease activity

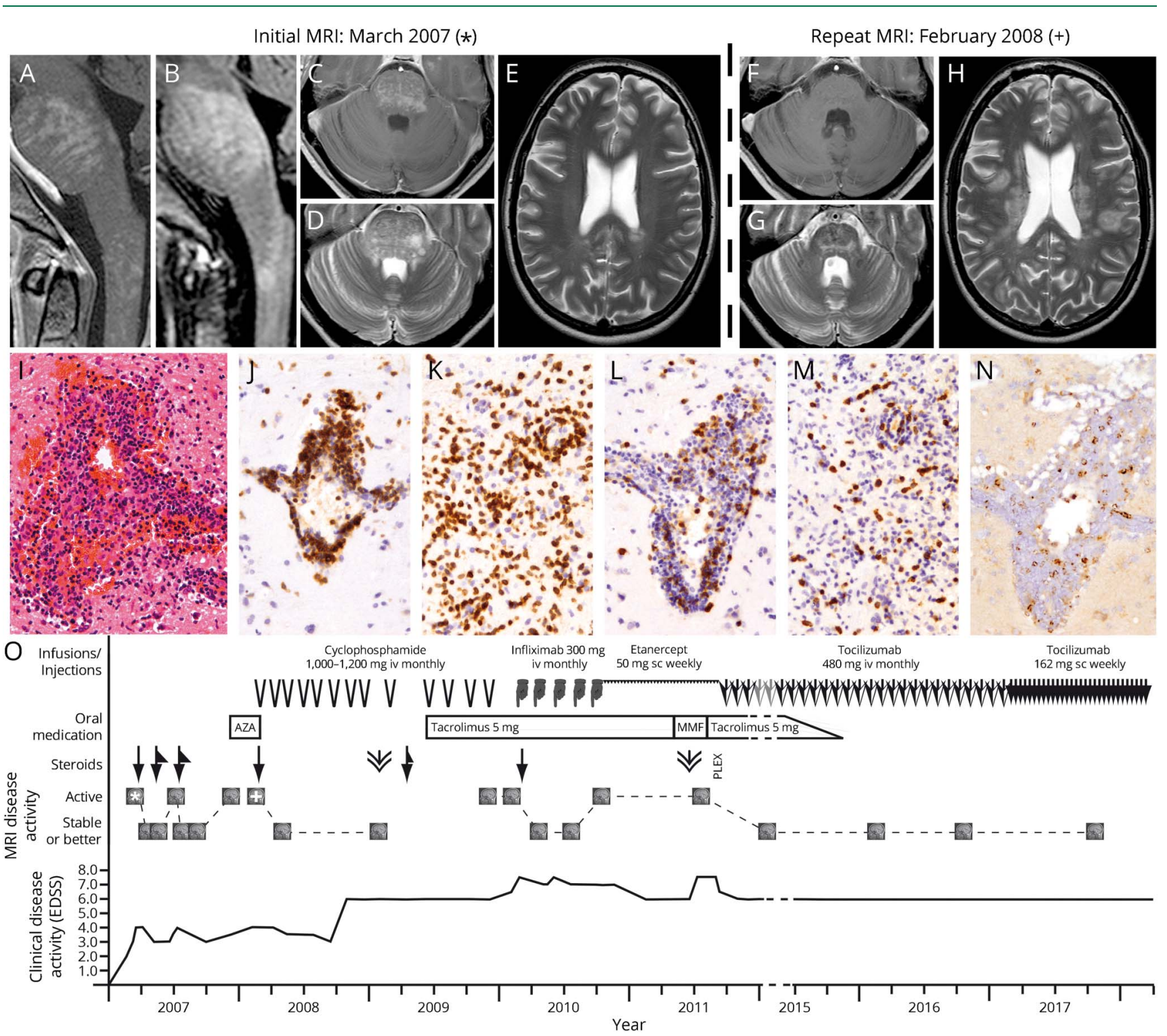

(A-E) Initial MRI 3/2007 showing typical "salt-and-pepper" like appearance of the pons and cervical myelon in gadolinium-enhanced T1-weighted (A) and fluidattenuated inverse recovery (FLAIR)-weighted (B) sagittal sections as well as in gadolinium-enhanced T1-weighted (C) and T2-weighted (D) axial sections. Axial T2-weighted section does not show significant supratentorial involvement at the onset of the disease (E). (F-H) MRI 2/2008, gadolinium-enhanced T1weighted (F) and T2-weighted (G) sections in the course of the disease. Axial T2-weighted section shows emerging supratentorial lesion burden in the course of the disease (H). (I-N): Histology and immunohistochemistry of the right temporal brain biopsy, 20x magnification. The HE stain shows a perivascular/ vascular inflammatory infiltrate (I), consisting of numerous T cells. Also, a parenchymal T-cell infiltrate is evident (CD3 stains, J, K). The minority of T cells are CD8-positive (CD8 stains, L, M), suggesting a CD4 predominance. Single cells stain for the marker Granzyme B (N) indicating cytotoxic T cells or natural killer cells. (O): Schematic course of treatment and disease activity. Infusions/injections: arrowheads: cyclophosphamide IV; hand symbols: infliximab IV; saw tooth pattern: etanercept SC; large arrows: tocilizumab IV; small arrows: tocilizumab SC. Oral medications are indicated in square boxes, MMF = Mycophenolate mophetil; AZA = azathioprine. Steroids: Arrows indicate methylprednisolone IV 3-5× $1000 \mathrm{mg}$. Triangles next to the arrows indicate oral tapering regimes. Double arrowheads indicate intrathecal crystalloid steroid injections. PLEX: Plasma exchange. MRI disease activity is indicated qualitatively as active (upper MRI symbols) or stable disease (lower MRI symbols). Clinical disease progression is displayed as Extended Disability Status Scale (EDSS) scores in the lower section of the graph. * and + symbols indicate the point of time of the $2 \mathrm{MRI}$ scans demonstrated in $\mathrm{A}-\mathrm{H}$.

Therefore, nonsteroidal disease-modifying therapy was initiated. Under azathioprine therapy, the patient experienced a significant increase in infratentorial and especially supratentorial Gadolinium-enhancing lesions. She was switched to cyclophosphamide, which at first lead to a significant radiologic improvement. However, symptoms progressed in 2009 under ongoing cyclophosphamide treatment, which was stabilized by addition of tacrolimus. After 13 cycles and a cumulative dose of $24,800 \mathrm{mg}$, cyclophosphamide therapy was discontinued in December 2009 with consecutive clinical and radiologic worsening.

During a trial of TNF- $\alpha$ blockers with monthly infliximab infusions in 2010, no new or enlarging brain lesions were 
observed even though there was continuing worsening of her gait dysfunction. Treatment with infliximab was stopped after an anaphylactic reaction and a following trial with etanercept was ineffective.

After a short phase of mycophenolate mofetil therapy and a 5day cycle of plasmapheresis, treatment with tocilizumab was initiated in October 2011 (initially $480 \mathrm{mg}$ IV monthly, then $162 \mathrm{mg}$ SC weekly since 2016), under which the patient's presentation rapidly stabilized and started to continuously improve both clinically and radiologically with no further signs of relapse (observation period: 6 years, last MRI brain and clinical follow-up in September 2017). The ongoing comedication with tacrolimus was tapered down and discontinued in 2015 without any symptomatic worsening.

\section{Discussion}

Our case fulfills the published diagnostic criteria of CLIPPERS ${ }^{1,2}$ and an extensive workup did not yield an alternative diagnosis. The development of prominent extrapontine supratentorial MRI lesions in the course of diseases has been observed in the majority of patients with CLIPPERS (8/12). ${ }^{3}$ Given the long observation period, this case report provides valuable insight in the efficiency of different steroid-sparing agents in one single case of CLIPPERS. Its key point is the long-standing relapse-free time period associated with tocilizumab treatment, which is remarkable given the patient's previous extensive disease course with various relapses and nonresponse to multiple agents including cyclophosphamide. Tocilizumab's immunologic effects are thought to be a result of the induction and expansion of B-regulatory cells as well as the decrease of expression of proinflammatory cytokines and chemokine genes. ${ }^{6}$ The beneficial effect of tocilizumab in CLIPPERS could therefore potentially be explained by its effect on the differentiation of $\mathrm{T}$ cells into effector or regulatory $\mathrm{T}$ cells with a significant increase of regulatory $\mathrm{T}$ cells. ${ }^{7}$ Although generally well-tolerated, use of tocilizumab requires a careful risk-benefit analysis, potential adverse events include severe infections and gastrointestinal perforations. ${ }^{6}$

\section{Author contribution}

T. Rempe: drafting/revising the manuscript and analysis or interpretation of data. J.S. Becktepe: data acquisition. I. Metz: drafting/revising the manuscript, accepts responsibility for the conduct of research and will give final approval, and histologic analysis. W. Brück: data acquisition, drafting/revising the manuscript, accepts responsibility for the conduct of research and will give final approval, and acquisition of data. K.H. Stürner: drafting/revising the manuscript and analysis or interpretation of data. G. Deuschl: data acquisition, study concept or design, accepts responsibility for the conduct of research and will give final approval, and study supervision. D. Berg: drafting/revising the manuscript, analysis or interpretation of data, and accepts responsibility for the conduct of research and will give final approval. R. Baron: study concept or design, analysis or interpretation of data, accepts responsibility for the conduct of research and will give final approval, and acquisition of data. R. Zeuner, data acquisition, analysis or interpretation of data, accepts responsibility for the conduct of research and will give final approval, and acquisition of data. F. Leypoldt: data acquisition, drafting/revising the manuscript, study concept or design, and analysis or interpretation of data.

\section{Study funding}

No targeted funding.

\section{Disclosure}

T. Rempe reports no disclosures. J.S. Becktepe received travel funding from Ipsen Pharma. I. Metz served on the advisory board of Roche; received speaker honoraria and travel funding from Biogen, Bayer Healthcare, Teva, Serono, Novartis, and Genzyme; received research support from Biogen; and received research support from the German Ministry for Education and Research. W. Bruck served on the advisory boards of Genzyme, Novartis, MedDay, Biogen, and Teva; received speaker honoraria from Teva, Sanofi, Genzyme, Novartis, Merck Serono, Biogen, Roche, and Bayer; served on the editorial boards of Therapeutic Advances in Neurologic Disorders, MS International and Neuropathology, and Applied Neurobiology; received research support from Teva, Novartis, Biogen, Genzyme, MedDay, German Research Foundation, German Ministry for Education and Research, Tschira Foundation, and German MS Society; and was an expert witness for Teva; K.H. Sturner received travel funding and speaker honoraria from Biogen, Merck, Roche, Sanofi, and Geynzyme; and received research support from Biogen and BMBF; G. Deuschl served on the scientific advisory boards of Medtronic and Boston Scientific; received travel funding and/or speaker honoraria from Boston Scientific; served as an editor for Movement Disorders and a coeditor for Aktuelle Neurologie; received publishing royalties from Thieme; and received research support from Medtronic and German Ministry of Education and Research; D. Berg served on the scientific advisory boards of Biogen, Bial, Lundbeck, and UCB Pharma; received travel funding and/or speaker honoraria from Destin, Pfizer, Lundbeck, Boehringer, Coppenrath, Grünenthal, JPND, Apotheken Wirtschaftsdienst, Asklepios Kliniken Hamburg, Bayer Vital, BIAL Deutschland, Weser, AbbVie Deutschland, TEVA, Dekanat der CAU, Ärztekemmer Schleswig-Hostein, Deutsche Parkinson Vereinigung, Janssen Neuroscience Network, Uniklinik, Humanitas Research Hospital-Mailand, Universitätsmedizin Rostock, Deutsche Gesellschaft für Neurologie, Universitästsklinikum Tübingen, Aklepios Klinik Altona, NDR Fernsehen, Segeberger Kliniken, Deutsche Parkinson Gesellschaft, Scandinavian Movement Disorder Society, and International Parkinson and Movement Disorder Society; served as a coeditor for DGNeurologie; served on the editorial boards of Movement Disorders Clinical Practice Journal and Neurological Research and Practice; served as an associate editor for the Journal of Parkinson's Disease; is a member of the scientific advisory 
board of Der Nervenarzt; consulted for Biogen, BIAL, Lundbeck, and UCB Pharma GmbH; served on the speakers' bureau of AbbVie, Biogen, BIAL, Lundbeck, and UCB Pharma; and received research support from Janssen, UCB, TEVA, Novartis, Lundbeck, BMWi, EU, Michael J. Fox Foundation, German Parkinson's Disease Society, and Damp Foundation; R. Baron served on the scientific advisory boards of AbbVie, Allergan, Astellas, AstraZeneca, Bayer-Schering, Biogen Idec, Biotest, AG, Boehringer Ingelheim Pharma GmbH \& Co. KG, Bristol-Meyers Squibb, Celegene, Daiichi Sankyo, Desitin, Eisai Co., Ltd., Galápagos, NV, Genentech, Genzyme GmbH, Glenmark Pharmaceuticals, Grünenthal $\mathrm{GmbH}$, Kyowa Kirin GmbH, Lilly GmbH, Medtronic, Merck, MSD GmbH, Mundipharma, Novartis, Pfizer, Sanofi Pasteur, Seqirus, TAD Pharma GmbH, Teva Pharma, Theranexus, and Vertex Pharmaceuticals Inc; received travel funding and/or speaker honoraria from Pfizer, Genzyme $\mathrm{GmbH}$, Grünenthal $\mathrm{GmbH}$, Mundipharma, Sanofi Pasteur, Medtronic Inc.Neuromodulation, Eisai Co.,Ltd., Lilly GmbH, Boehringer Ingelheim Pharma GmbH \& Co. KG, Astellas, Desitin, Teva Pharma, Bayer- Schering, MSD GmbH, Seqirus, Novartis, TAD Pharma GmbH; served on the editorial boards of Nature Reviews Neurology, European Journal of Pain; consulted for Pfizer, Genzyme GmbH, Grünenthal $\mathrm{GmbH}$, Mundipharma, Allergan, Sanofi Pasteur, Medtronic, Eisai, Lilly $\mathrm{GmbH}$, Boehringer Ingelheim Pharma GmbH \& Co. KG, Astellas, Novartis, Bristol-Myers Squibb, Biogen Idec, AstraZeneca, Merck, AbbVie, Daiichi Sankyo, Glenmark Pharmaceuticals, Seqirus, Teva Pharma, Genentech, Galápagos NV, Kyowa Kirin GmbH, Vertex Pharmaceuticals Inc., Biotest AG, Celgene, Desitin, and Theranexus; served on the speakers' bureau of Pfizer, Genzyme $\mathrm{GmbH}$, Grünenthal $\mathrm{GmbH}$, Mundipharma, Sanofi Pasteur, Medtronic Inc.-Neuromodulation, Eisai Co.,Ltd., Lilly GmbH, Boehringer Ingelheim Pharma GmbH \& Co. KG, Astellas, Desitin, Teva Pharma, BayerSchering, MSD GmbH, Seqirus, Novartis, and TAD Pharma $\mathrm{GmbH}$; received research support from AbbVie, Allergan, Astellas, AstraZeneca, Bayer-Schering, Biogen Idec, Biotest, AG, Boehringer Ingelheim Pharma $\mathrm{GmbH} \&$ Co., KG, Bristol-Meyers, Squibb, Celegene, Daiichi, Sankyo, Desitin, Eisai, Co., Ltd., Galápagos, NV, Genentech, Genzyme GmbH, Glenmark Pharmaceuticals, Grünenthal $\mathrm{GmbH}$, Kyowa Kirin GmbH, Lilly GmbH, Medtronic, Merck MSD GmbH,
Mundipharma, Novartis, Pfizer, Sanofi Pasteur, Seqirus, TAD Pharma GmbH, Teva Pharma, Theranexus, Vertex Pharmaceuticals Inc.; is a member of the IMI "Europain" collaboration and industry members of this are: AstraZeneca, Pfizer, Esteve, UCB Pharma, Sanofi-Aventis, Grünenthal GmbH, Eli Lilly, and Boehringer Ingelheim Pharma GmbH \& Co. KG, German Federal Ministry of Education and Research (BMBF): member of the ERA_NET NEURON/IM-PAIN Project (01EW1503), German Research Network on Neuropathic Pain (01EM0903), NoPain system biology (0316177C), and member of the EU Project No 633491: DOLORisk and EU: IMI 2 Paincare; and receives license fees from Pfizer; R. Zeuner received speaker and travel honoraria from Roche; F. Leypoldt served on the scientific advisory boards of Roche and Biogen; received travel funding and/or speaker honoraria from Grifols, Teva, Biogen, Fresenius, Bayer, Novartis, Merck, and Roche; and performs commercial antibody testing for the Institute of Laboratory Medicine, University Hospital Schleswig-Holstein, Campus Kiel, Germany. Full disclosure form information provided by the authors is available with the full text of this article at Neurology.org/NN.

\section{Publication history}

Received by Neurology: Neuroimmunology \& Neuroinflammation September 11, 2018. Accepted in final form January 8, 2019.

\section{References}

1. Dudesek A, Rimmele F, Tesar S, et al. CLIPPERS: chronic lymphocytic inflammation with pontine perivascular enhancement responsive to steroids. Review of an increasingly recognized entity within the spectrum of inflammatory central nervous system disorders. Clin Exp Immunol 2014;175:385-396.

2. Pittock SJ, Debruyne J, Krecke KN, et al. Chronic lymphocytic inflammation with pontine perivascular enhancement responsive to steroids (CLIPPERS). Brain 2010, 133:2626-2634

3. Taieb G, Duflos C, Renard D, et al. Long-term outcomes of CLIPPERS (chronic lymphocytic inflammation with pontine perivascular enhancement responsive to steroids) in a consecutive series of 12 patients. Arch Neurol 2012;69:847-855.

4. Taieb G, Allou T, Labauge P. Therapeutic approaches in CLIPPERS. Curr Treat Options Neurol 2017;19:17.

5. Simon NG, Parratt JD, Barnett MH, et al. Expanding the clinical, radiological and neuropathological phenotype of chronic lymphocytic inflammation with pontine perivascular enhancement responsive to steroids (CLIPPERS). J Neurol Neurosurg Psychiatry 2012;83:15-22.

6. Scott LJ. Tocilizumab: a review in rheumatoid arthritis. Drugs 2017;77: 1865-1879.

7. Kikuchi J, Hashizume M, Kaneko Y, Yoshimoto K, Nishina N, Takeuchi T. Peripheral blood $\mathrm{CD} 4(+) \mathrm{CD} 25(+) \mathrm{CD} 127$ (low) regulatory $\mathrm{T}$ cells are significantly increased by tocilizumab treatment in patients with rheumatoid arthritis: increase in regulatory $\mathrm{T}$ cells correlates with clinical response. Arthritis Res Ther 2015 $17: 10$. 


\section{Neurology \\ Neuroimmunology \& Neuroinflammation}

A case of CLIPPERS syndrome responsive to tocilizumab

Torge Rempe, Jos Steffen Becktepe, Imke Metz, et al.

Neurol Neuroimmunol Neuroinflamm 2019;6;

DOI 10.1212/NXI.0000000000000545

This information is current as of February 4, 2019

\section{Updated Information \& Services}

References

Citations

Permissions \& Licensing

Reprints including high resolution figures, can be found at: http://nn.neurology.org/content/6/3/e545.full.html

This article cites 7 articles, 1 of which you can access for free at: http://nn.neurology.org/content/6/3/e545.full.html\#\#ref-list-1

This article has been cited by 1 HighWire-hosted articles: http://nn.neurology.org/content/6/3/e545.full.html\#\#otherarticles

Information about reproducing this article in parts (figures,tables) or in its entirety can be found online at: http://nn.neurology.org/misc/about.xhtml\#permissions

Information about ordering reprints can be found online: http://nn.neurology.org/misc/addir.xhtml\#reprintsus

Neurol Neuroimmunol Neuroinflamm is an official journal of the American Academy of Neurology.

Published since April 2014, it is an open-access, online-only, continuous publication journal. Copyright

Copyright (C) 2019 The Author(s). Published by Wolters Kluwer Health, Inc. on behalf of the American Academy of Neurology.. All rights reserved. Online ISSN: 2332-7812.

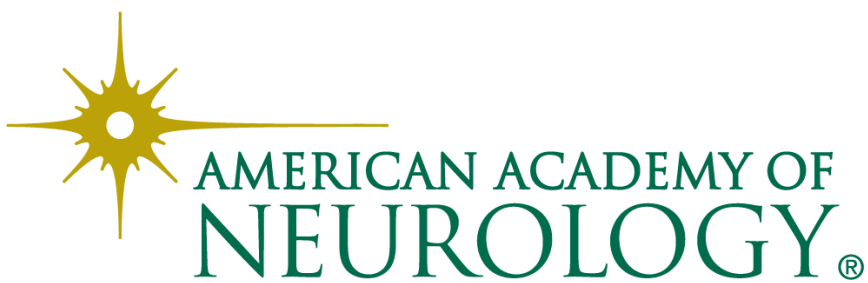

